\title{
Dental Treatment for Low Back and Hip Pain in a Long-Distance Runner: A Case Report
}

\author{
Yoshiro Fujii \\ Shin-Kobe Dental Clinic, Kobe, Japan \\ Email: shin-kobe-dentalclinic@s9.dion.ne.jp
}

How to cite this paper: Fujii, Y. (2021) Dental Treatment for Low Back and Hip Pain in a Long-Distance Runner: A Case Report. Advances in Physical Education, 11, 135-140. https://doi.org/10.4236/ape.2021.111010

Received: December 11, 2020

Accepted: February 23, 2021

Published: February 26, 2021

Copyright $\odot 2021$ by author(s) and Scientific Research Publishing Inc. This work is licensed under the Creative Commons Attribution International License (CC BY 4.0).

http://creativecommons.org/licenses/by/4.0/

\begin{abstract}
Occlusion and mandibular positions substantially affect full-body functioning and performance in sports. This report illustrates the case of a 27 -year-old female long-distance runner who had intermittent lower back and hip pain. Since her bilateral maxillary first molars were missing, small partial dentures were placed in the position of those missing molars in order to improve occlusion. Even right after the right-side denture was placed, her performance on the straight leg raising test and the strength of the iliopsoas muscle in the supine position improved. Her performance improved further after the left-side denture was placed. This report shows that occlusal restoration causes a definite improvement in body function, even in cases of small missing teeth.
\end{abstract}

\section{Keywords}

Long Distance Runner, Lower Back Pain, Hip pain, Partial Denture, Iliopsoas Muscle, The Bi-Digital O-Ring Test, Straight Leg Raising (SLR) Test

\section{Introduction}

The occlusion and mandibular positions affect both full-body functioning and sports performance (Watanabe et al., 1998; Fujii, 2016; Fujii, 2017; Fujii, 2019; Fujii, 2020; Miyaji, 2020; Mehta, \& Forgione, 1996). In this report, I describe the effectiveness of dental treatment in a runner with intermittent low back and hip pain.

\section{Methods}

\subsection{Subject}

The patient is a 27-year-old female long-distance runner who felt intermittent 
dull in her low back and hip pain after excessive exercise. In the previous few years, she had often taken an acupuncture treatment after practice because it was temporarily effective. Then she had not visited any medical investigations such as radiography, computed tomography, or magnetic resonance imaging by a physician or an orthopedist because she felt less pain when she did not do some exercises. However, when she tried to join training, she could not practice enough because of her back and hip pain. She struggled that she hasn't been able to break her self-record for the last three years. She wanted to improve her sports performance situation as breaking her own record.

\subsection{Methodology}

The occlusion of her molars was inappropriate because of the loss of the crowns of the upper bilateral first molars (Figure 1). Problems with these teeth might have been arisen approximately 5 years earlier, though she was not aware of the relationship between malocclusion and her symptoms of body pains.

The upper second molars were tilting mesially and gradually moved into the space that the first molars had occupied (Figure 1); Despite this situation, she did not feel structural abnormalities in the oral cavity or temporomandibular joint. She also was able to chew without any problems. When a little cotton was inserted into the position of the missing tooth, her grip in the Bi-Digital O-Ring Test became stronger. In this attempt, placing a little cotton means applying a prothesis as instead of denture, whereas strength of the grip in the Bi-Digital O-Ring Test means its effectiveness for her comfortable muscle movement and body function. Therefore, it can be distinguished that her missing tooth must have affected her body functions. To treat this condition, locating partial dentures for both sides of the missing teeth is necessary.

Firstly, the root residue of the upper right molar should be extracted because there was dental caries. I took an impression for a denture with silicone rubber 18 days later; after the socket (indentation after tooth pulling) healed.

Secondly, a small resin partial denture with metal clasp (Quintess $87^{\circledR}$; Yamakin Ltd., Tokyo, Japan, including $87.0 \%$ gold, $10.6 \%$ platinum, $0.3 \%$ silver, $2.1 \%$ other metals) was arranged as a prosthesis for the missing molars (Figure 2). The material of the denture was chosen very carefully in terms of color and metal, as well as its occlusal matching condition to find the most appropriate things for the patient, and those were determined by using the Bi-Digital O-Ring Test (Fujii, 2017; Fujii, 2019) (Figure 3). According to the result of the test, the denture materials which features maximized the patient's grip strength were chosen.

Finally, I contrasted lower limb flexibility and lower limb muscle strength without the denture and with it. The straight leg raising (SLR) test was used to measure lower limb flexibility: While the patient was lying on her back on a bed, I lifted her leg while the knee was straight. The strength of the iliopsoas muscle was measured in the supine position with a handheld dynamometer ( $\mu$ Tas F-1; Anima Ltd., Tokyo, Japan) during break testing (Jeon, 2019) (Table 1). 


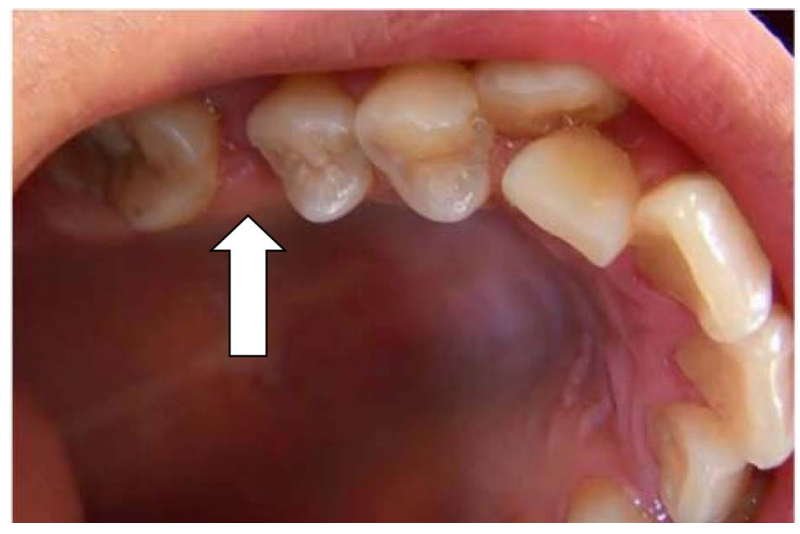

Figure 1. There was a missing tooth after removing a root residue of the upper right first molar. The upper second molars mesially tilted and the space of the first molar had decreased (arrow).

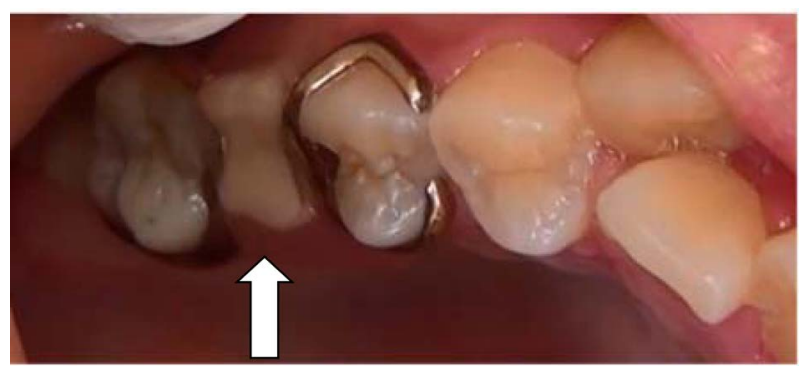

Figure 2. The small partial denture was located to improve occlusion (arrow).

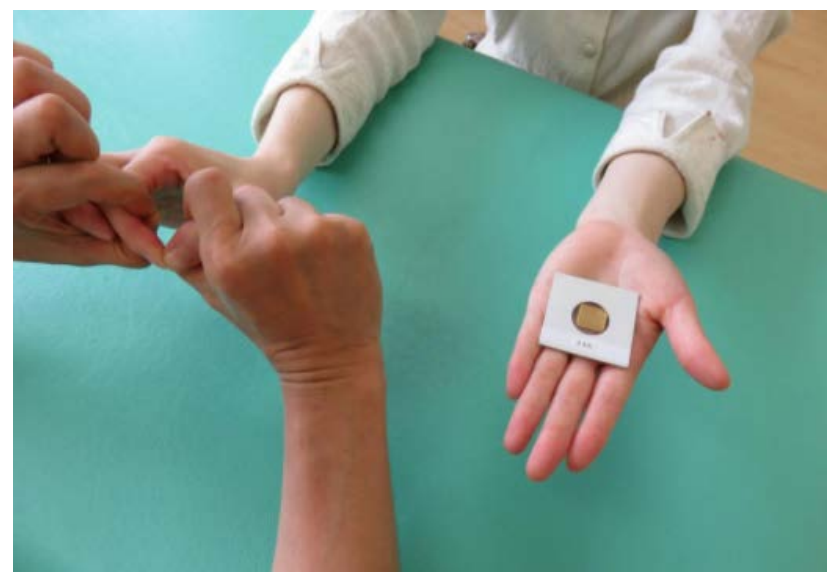

Figure 3. The Bi-Digital O-ring Test. The substance was placed on the subject's palm. Then, the subject made an O-Ring with subject's thumb and another finger of her opposite hand, which the author tried to split.

Table 1. Data comparison before and after treatment.

\begin{tabular}{ccccc}
\hline & SLR (right) & SLR (left) & $\begin{array}{c}\text { iliopsoas muscle } \\
\text { strength (right) }\end{array}$ & $\begin{array}{c}\text { iliopsoas muscle } \\
\text { strength (left) }\end{array}$ \\
\hline Before treatment & $67^{\circ}$ & $55^{\circ}$ & $9.9 \mathrm{~kg}$ & $13.7 \mathrm{~kg}$ \\
After treatment & $90^{\circ}$ & $90^{\circ}$ & $16.1 \mathrm{~kg}$ & $15.3 \mathrm{~kg}$ \\
Improvement rate & $34.3 \%$ & $63.6 \%$ & $62.6 \%$ & $11.7 \%$ \\
\hline
\end{tabular}




\section{Results}

In the SLR test, raising of the right leg improved from $67^{\circ}$ before treatment to $90^{\circ}$ after treatment; raising of the left leg improved from $55^{\circ}$ before treatment to $90^{\circ}$ after treatment; right-sided iliopsoas muscle strength improved from $9.9 \mathrm{~kg}$ to $16.1 \mathrm{~kg}$ (62.6\% improvement); and left-sided iliopsoas muscle strength improved from $13.7 \mathrm{~kg}$ before treatment to $15.3 \mathrm{~kg}$ after treatment $(11.7 \% \mathrm{im}$ provement).

A full video of the experimental procedure is freely available online at the following link: https://www.youtube.com/watch?v=C4Fm7Qae3Ww "Only a little denture improved body condition" (last checked: 14 May 2020).

After this treatment, the subject felt very little pain around her low back and hip and increased her stride when running. Her sports performance improved after insertion of both prosthesis and treatment of dental caries. The 3-year prognosis for her condition including SLR and iliopsoas muscle strength is good. During this term, she broke her self-record for the 5000 meters as from 16'33" to $15^{\prime} 50 "$.

\section{Discussion}

In this study, I examined how restoring missing teeth and improving occlusion may help improve muscle strength and flexibility of the lower body. The SLR test was used to measure lower limb flexibility, and the iliopsoas muscle was used to measure lower limb muscle strength. The iliopsoas muscle functions as a hip flexor and as a dynamic stabilizer of the hip joint during walking (Jeon, 2019) and active leg raising (Scott, Bond, Sisto, \& Nadler, 2004). In addition, the iliopsoas muscle helps maintain the continuous axis of the femur head in the hip joint during hip extension and external rotation (Jeon, 2019). Therefore, increasing the strength of the iliopsoas muscle is considered important in improving the sports performance of runners. Improvement in the SLR test may be indicative of improved sports performance (Devillé, van der Windt, Dzaferagic, Bezemer, \& Bouter, 2000). Improvements in iliopsoas strength and in flexibility help increasing stride during running, and thus alleviate the symptoms of low back and hip pain. These improvements, which appeared after only a small restoration of the occlusion, suggest that occlusion contributes to the function of the whole body. The results of this study suggest that even a slight improvement in occlusion may alleviate back pain.

Anatomically, the trigeminal nerve, which innervates the face and oral cavity, is the largest of the 12 pairs of cranial nerves. Thus a great deal of information is transmitted to the brain from the mouth via the trigeminal nerve. Julià-Sánchez et al. reported that afferent signals from the oral cavity that are related to dental occlusion effectively contribute to balance control when more external perturbations are present (Julià-Sánchez, Álvarez-Herms, \& Burtscher, 2019) and also reported that proprioceptor information about the position and movement of the head and neck in space are mediated by dental occlusion via the trigeminal 
nerve, principally the mesencephalic root of the trigeminal nerve (Thomas, Thomas, \& Thomas, 2019). Treatment of occlusion involves nerve reflexes, which may explain the results seen in our patient.

\section{Practical Applications}

The results of this case show that a slight improvement in occlusal condition helps to improve sports performance. If the dental treatment is done well, there will be no pain or side effects, and a long-lasting effect can be expected. Therefore, if the previous treatments do not give sufficient results, the dental treatment may be worthy trying. Furthermore, it seems that better support may be provided to athletes by coordinating dentistry with medical departments and acupuncture etc. When weight training is performed to increase muscle strength, joint flexibility may decrease. However, this method has the advantage that the muscle strength is increased immediately, and the joint flexibility is also increased.

\section{Conclusion}

A 27-year-old long-distance female runner who had intermittent lower back and hip pain took occlusal treatment by means of locating a small partial denture. Just after the denture was placed, her performance improved dramatically. According to a 3-year follow-up, her physical condition remains in very good. She set a new self-record that shortened 43 seconds in the 5000-meter race.

\section{Acknowledgements}

We would like to give a special thanks to Enago (www.enago.jp) for the English language review. We thank the participant of this research for their valuable contributions.

\section{Conflicts of Interest}

The author declares no conflicts of interest regarding the publication of this paper.

\section{References}

Devillé, W. L., van der Windt, D. A., Dzaferagić, A., Bezemer, P. D., \& Bouter, L. M. (2000). The Test of Lasègue: Systematic Review of the Accuracy in Diagnosing Herniated Discs. Spine, 25, 1140-1147. https://doi.org/10.1097/00007632-200005010-00016

Fujii, Y. (2016). Two Cases of Severe Dementia Showing Dramatic Improvement after Denture Placement. Advances in Alzheimer's Disease, 5, 46-52. https://doi.org/10.4236/aad.2016.52004

Fujii, Y. (2017). Severe Dermatitis Might Be Caused by a Cross-Reaction between Nickel and Palladium and Dental Amalgam Resolved Following Removal of Dental Restorations. Clinical Case Reports, 5, 795-800. https://doi.org/10.1002/ccr3.938

Fujii, Y. (2019). Evaluation of a Mouthguard Customized Using the Occlusal Position during Maximal Grip Strength to Improve Sports Performance. A Case Report. Case 
Reports in Clinical Medicine, 8, 147-151. https://doi.org/10.4236/crcm.2019.86017

Fujii Y. (2020). Treatment of Elderly Bedridden Patients with Removable Dentures to Promote Their Daily Physical Activities: A Case-Control Study. Advances in Aging Research, 9, 116-125. https://doi.org/10.4236/aar.2020.96009

Gelb, H., Mehta, N. R., \& Forgione, A. G. (1996). The Relationship between Jaw Posture and Muscular Strength in Sports Dentistry: A Reappraisal. Cranio, 14, 320-325. https://doi.org/10.1080/08869634.1996.11745984

Jeon, I. C. (2019). Comparison of Test-Retest Measurement Reliability of Iliopsoas Strength between Break and Make Test in Subjects with Lumbar Extension Syndrome. Journal of Musculoskeletal Science and Technology, 3, 54-58. https://doi.org/10.29273/jmst.2019.3.2.54

Julià-Sánchez, S., Álvarez-Herms, J., \& Burtscher, M. (2019). Dental Occlusion and Body Balance: A Question of Environmental Constraints? Journal of Oral Rehabilitation, 46, 388-397. https://doi.org/10.1111/joor.12767

Miyaji, S. (2020). Lower Back Pain and Forearm Tendinitis Linked to Irritation of Oral Mucosa by Teeth. Case Reports in Clinical Medicine, 9, 295-302.

https://doi.org/10.4236/crcm.2020.99042

Scott, D. A., Bond, E. Q., Sisto, S. A., \& Nadler, S. F. (2004). The Intra- and Interrater Reliability of Hip Muscle Strength Assessments Using a Handheld Versus a Portable Dynamometer Anchoring Station. Archives of Physical Medicine and Rehabilitation, 85, 598-603. https://doi.org/10.1016/j.apmr.2003.07.013

Thomas, N. R., Thomas, T. D., \& Thomas, N. R. (2019). The Relationship between the Dental Occlusion, Upper Cervical Spine and Temporomandibular Joints Prior to and Following Tens Treatment in Thirty Six Patients Suffering from Temporomandibular Disorder. Oral Health Care, 4, 1-8. https://doi.org/10.15761/OHC.1000156

Watanabe, E. K., Yatani, H., Kuboki, T., Matsuka, Y., Terada, S., Orsini, M. G., \& Yamashita, A. (1998). The Relationship between Signs and Symptoms of Temporomandibular Disorders and Bilateral Occlusal Contact Patterns during Lateral Excursions. Journal of Oral Rehabilitation, 25, 409-415. https://doi.org/10.1046/j.1365-2842.1998.00262.x 